\title{
Olive fruit fly populations measured in Central and Southern California
}

\section{Richard E. Rice \\ Phil A. Phillips \\ Judy Stewart-Leslie \\ G. Steven Sibbett}

$\nabla$
The olive fruit fly was detected in Southern California in October 1998. This nonnative pest, which can render fruit unmarketable, has since moved throughout California and is now believed to be present wherever olives are grown in the state. Seasonlong trapping of adult flies in the San Joaquin Valley, and Ventura and Santa Barbara counties in 2001 and 2002 showed similarities in seasonal phenology, but also differences primarily due to varying temperatures and fruit availability. In the San Joaquin Valley, fly activity declined as maximum daily temperatures rose above $90^{\circ} \mathrm{F}$, but increased when temperatures were between $70^{\circ} \mathrm{F}$ and $85^{\circ} \mathrm{F}$. On the Southern California coast, the combination of available, susceptible fruit and moderate climate throughout the year may allow continuous reproduction of OLF with six or perhaps even seven generations per year.

$\mathrm{T}_{\mathrm{i} \text { h }}^{\mathrm{h}}$ he olive fruit fly (OLF or olive fly) is considered the most serious insect pest of olive fruit in the world. Historically, it infested Mediterranean areas of southern Europe, North Africa and the Middle East, where olives have been cultivated for thousands of years (Economopoulos 2002). It is also found on the Indian subcontinent, Mexico, South Africa and other regions of Africa where wild olives grow.

A feral olive fruit fly, Bactrocera oleae (Gmelin), was first detected in North America on Oct. 19, 1998, in an orange tree in west Los Angeles. This fly was caught in a McPhail bait (food lure)

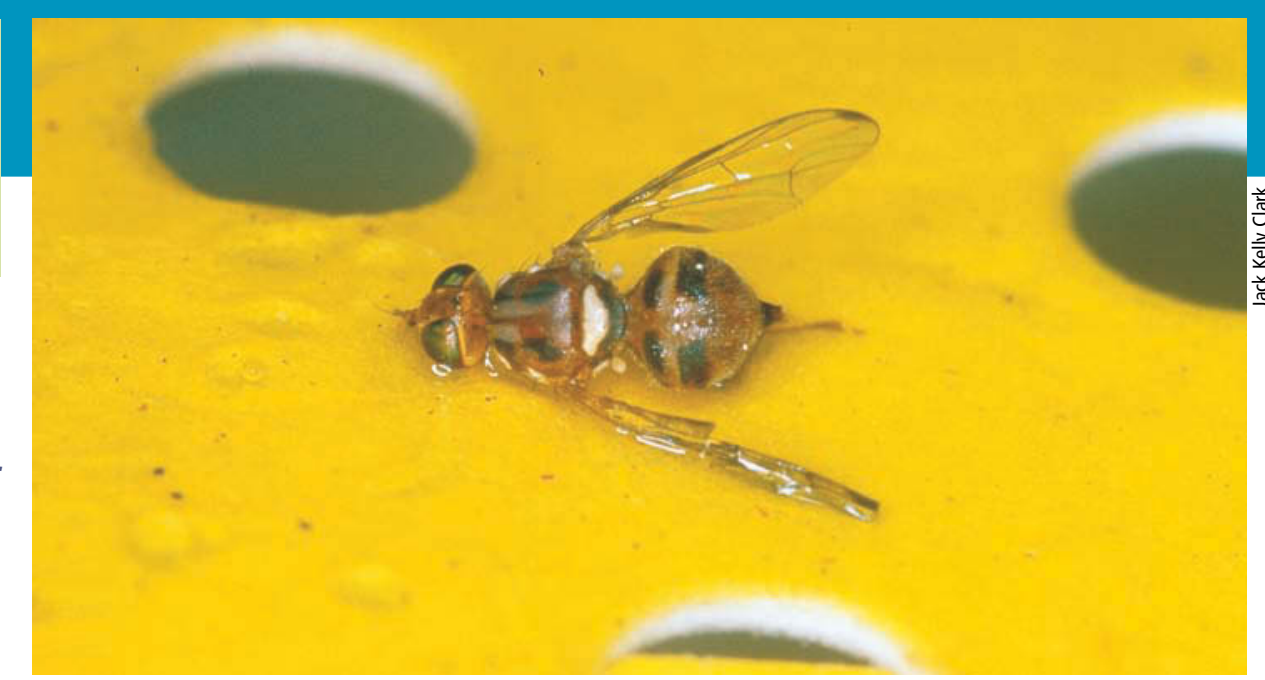

Long a pest in the Mediterranean region, the nonnative olive fruit fly was first detected in California in 1998. Although extensive research has been conducted abroad, California-specific trapping data was needed on the fly's seasonal occurrence and geographic distribution. Above, A female olive fly on a yellow sticky trap.

trap, which is commonly used by regulatory agencies for detecting insects such as Mexican fruit fly that do not respond to specific lures or attractant chemicals. Subsequent delimitation (detection and distribution) trapping found that the coastal counties from Santa Barbara south to San Diego, and the inland counties of Riverside and San Bernardino were generally infested with olive fly.

On Sept. 14, 1999, a male olive fly was trapped in a commercial olive grove in southern Tulare County in the San Joaquin Valley, the major production area for table olives in California. California produces $99 \%$ of commercial olives grown in the United States, with 134,000 tons of olives on 36,000 acres in 2001, for a total value of $\$ 90$ million (CDFA 2002). Intensive trapping in 1999 failed to detect any additional flies in the surrounding area. The apparent absence of additional flies was reassuring to olive growers and led to speculation that perhaps the olive fly could not move from Southern California into the central and northern areas of the state, or would be severely restricted in its establishment due to the hot, dry climate of the interior.

In May 2000, however, additional flies were trapped in Tulare County, and in adjacent Kern and Fresno counties. New OLF detections were also reported along the coast north of Santa Barbara County, in San Luis Obispo County and eventually Monterey County. Following these spring collections in the San Joaquin Valley and Central Coast, fly populations and detections increased rapidly in these areas through 2000 (Rice 2000).

Detection

trapping by state and county agricultural officials was terminated by mid-2000 due to the high numbers of flies being collected. An initial trapping study in Ventura and Santa Barbara counties showed low early-season collections followed by higher summer and fall populations (Phillips and Rice 2001).

With the long history and pest status of olive fly in Mediterranean countries, extensive research on its biology, ecology and control are available in the European literature. In order to use this large database effectively, however, California olive growers wanted to obtain state-specific information on the fly's seasonal occurrence and geographic distribution. Consequently, the California Olive Committee (COC), representing table olive growers, initiated a 2-year trapping program in commercial groves in the San Joaquin Valley and provided partial support for a regional trapping 

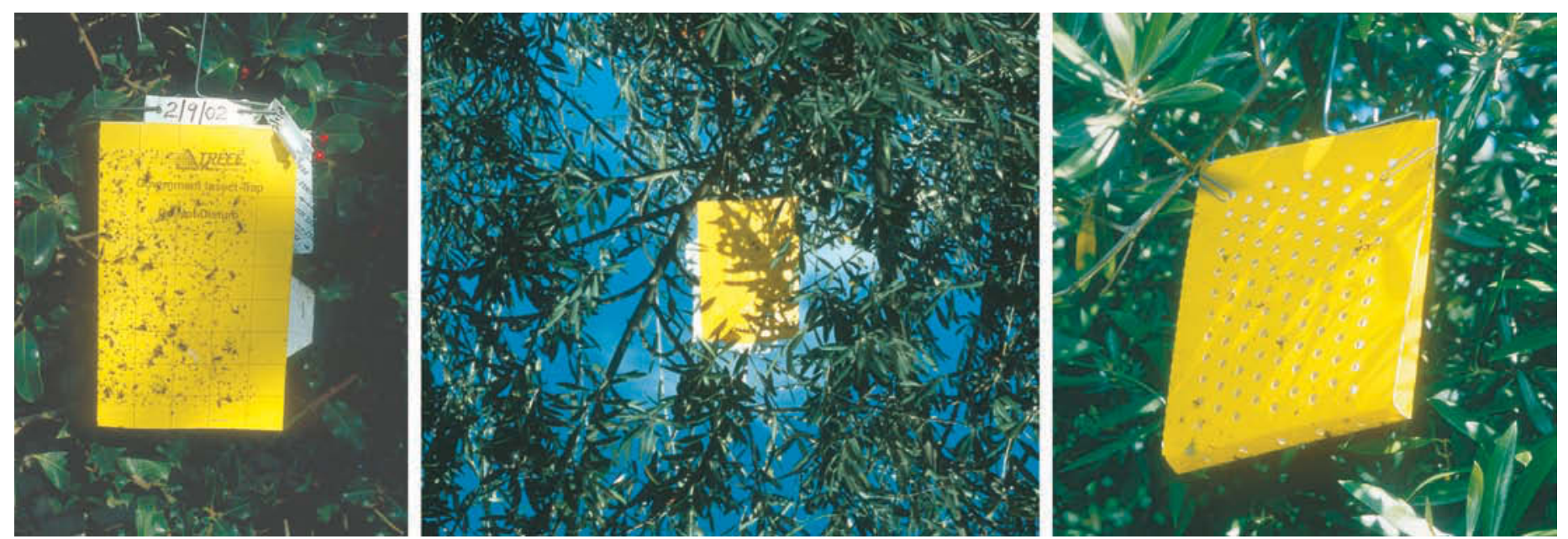

Researchers trapped for olive fruit fly in the San Joaquin Valley, and Santa Barbara and Ventura counties, using yellow sticky traps, above. In each replicate, traps were baited with ammonium bicarbonate food attractant lures plus an olive fly spiroketal pheromone lure, left.

project in coastal Santa Barbara and Ventura counties. We conducted less extensive OLF trapping in urban and noncommercial sites in Tulare and Fresno counties to supplement the COCfunded data.

Our study objectives were to expand on preliminary information about seasonal and geographic distribution of OLF in Central and Southern California (Phillips and Rice 2001; Rice 2000), evaluate and compare fly collections with different types of lures, and help develop possible control strategies in commercial production areas based on fly phenology and crop development.

\section{Olive fly trapping projects}

The commercial trapping project — directed by Pest Management Associates (PMA) in Exeter, Calif. — was established in 10 olive groves on the east side of the San Joaquin Valley from northern Kern County to Madera County, over approximately 110 miles. Several of these groves were located in rolling foothills at the western base of the Sierra Nevada; others were on the flat valley floor.

In nine groves, 10 yellow-panel "ChamP" sticky traps were placed within the perimeter of each grove in five equidistant paired-trap replicates. Traps in each replicate were placed three trees apart, four to seven trees inside the orchard, 8 to 10 feet high in open shade. (Open shade refers to trap placement in constant shade within the tree canopy, but with clear or unrestricted access to the trap by responding insects and no nearby leaves or limbs for the insect to land on instead of the trap.) Traps were placed on the north side of trees during hot weather (June to September) and on the south side in cooler weather.

In each replicate, one trap was baited with an ammonium bicarbonate food attractant lure (Suterra LLC [Consep], Bend, Ore.) plus an olive fly spiroketal pheromone lure (Vioryl S.A., Athens, Greece). The second trap in each replicate was baited only with the ammonium bicarbonate food lure. The 10th commercial grove in the COC/PMA project was a small organic planting with enough area for only six traps (three reps). A total of 96 traps were included in this study.

Trap sites remained the same during the 2-year study. All commercial olive groves except the organic grove were treated in 2001 and 2002 with spinosad bait sprays (GF-120, Dow AgroSciences) at recommended rates to control OLF. Upon recommendations from European researchers, bait spray treatments were initiated at the beginning of olive "pit-hardening," which is presently determined by periodically slicing carefully through small, developing olives with a sharp blade until resistance or hardening of the olive seed (pit) is detected. At this stage, olives are considered susceptible to infestation by OLF. Using this method, pit-hardening in the southern San Joaquin Valley was identified in Manzanillo fruit on June 13, June 18 and June 19 in 2001, 2002 and 2003, respectively. Treatments were applied at 2-week intervals through harvest in
September or October. In addition to the 10 commercial groves (PMA data), we monitored 15 noncommercial, untreated urban and rural sites in Tulare County with single traps having both lure types (Tulare), as well as three untreated urban and rural sites Fresno County with two traps per site and both lure types (Fresno).

Traps in all three San Joaquin Valley studies were initially placed in the field in March 2001 and inspected for OLF at weekly intervals through November 2001. Trapping continued during winter 2001 and through 2002, although traps were serviced at only 2-week intervals from December 2001 through mid-February 2002 due to cold weather and low fly collections. Collected flies were sexed and comparisons made between traps with both lure types and only the ammonium bicarbonate food lures in the PMA commercial groves.

The food lures were replaced at 2-week intervals in hot weather, and every 3 weeks in cool weather; spiroketal lures were replaced at 4-month intervals throughout the year. Trap bodies were replaced as needed to minimize contamination by nontarget insects, especially muscoid flies responding to the ammonium bicarbonate lures, and other insects responding to the yellow trap color.

Along with trapping in the San Joaquin Valley, we maintained a similar project in Ventura and Santa Barbara counties in noncommercial urban and rural sites throughout 2001 and 2002. We wanted to compare OLF phenology 


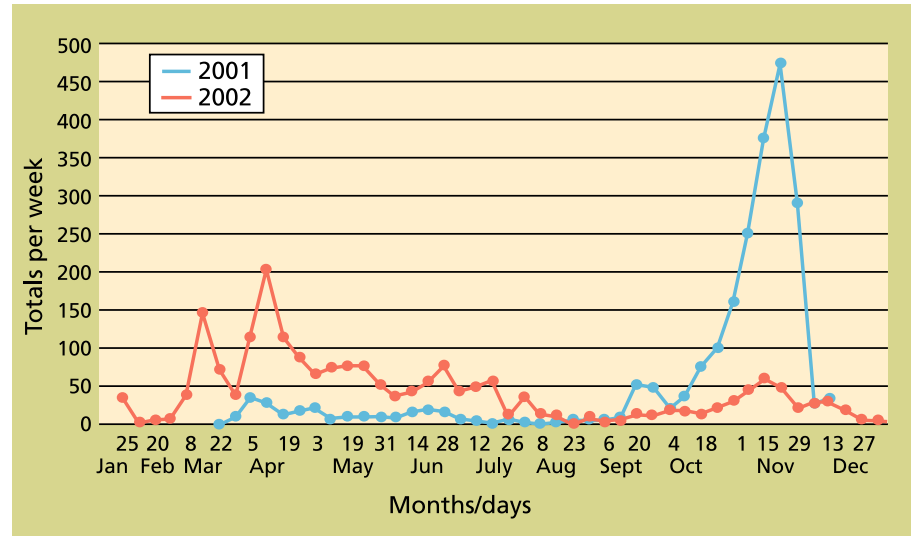

Fig. 1. Olive fly trapping in the San Joaquin Valley; all traps (117) combined, 2001 and 2002.

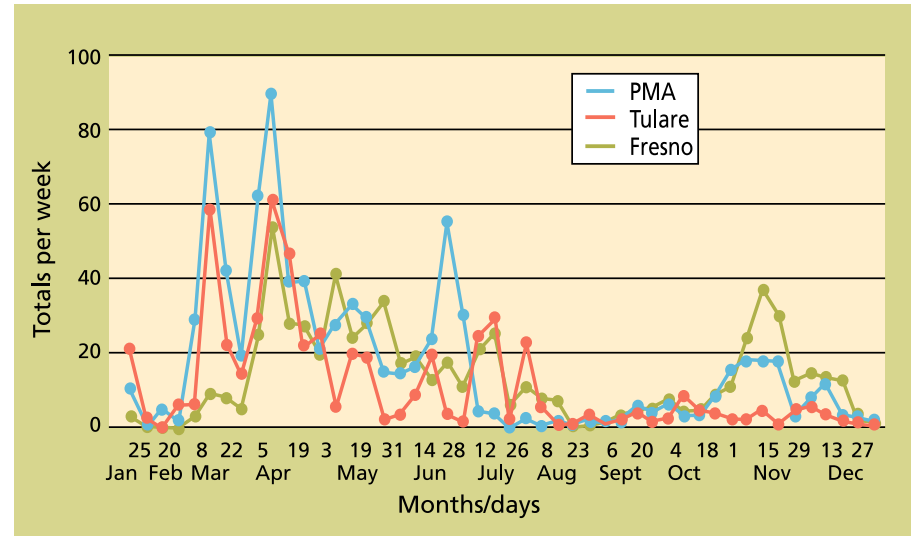

Fig. 2. Olive fly collections in commercial olives (PMA, 96 traps) and urban/rural traps (Tulare County, 15 traps; Fresno County, six traps) in the San Joaquin Valley, 2002. and collection data between the two regions because of expected differences in fly bionomics between coastal and interior valley climates (Michelakis 1990; Todd 1929). In Ventura County, eight trap sites (replicates) were monitored with two yellow-panel (ChamP) sticky traps, one with only the ammonium bicarbonate lure and one with both ammonia and pheromone lures, for a total of 16 traps. In Santa Barbara County two traps with lures as described for Ventura were maintained at each of seven sites for a total of 14 traps. Trapping protocols as previously described were used in this study, except traps were serviced and flies counted every week rather than biweekly through the winter months.

\section{San Joaquin Valley trap data}

In general, the observed seasonal activity of OLF based on their attraction to yellow-panel sticky traps with food and pheromone lures in California was similar to reports of olive fly phenology in Mediterranean areas (Economopoulos et al. 1982; Longo and Benfatto 1982; Ramos et al. 1982; Kapatos and Fletcher 1984; Haniotakis 1986; MontielBueno 1986). In the San Joaquin Valley, the data showed relatively high adult fly activity in late winter/early spring with a decline in April and May. This was followed by a smaller OLF flight in June, and then a decline to very low, sometimes almost nondetectable levels during the hot summer months (July to early September)(figs. 1, 2). Beginning in September, fly populations again began to increase and reached very high levels in 2001, but not in 2002, before the onset of cool weather in November. Al- though relatively few flies were caught from December 2001 to February 2002, at least one fly was trapped somewhere in the San Joaquin Valley every week during this period.

In early March 2002, OLF numbers began to increase again, representing continuing activity of overwintered adult flies. Another peak in April, possibly representing flies emerging from overwintered pupae, was followed by a small flight in May, representing the first generation of flies that developed in fruit remaining on trees from the previous crop year (Economopolous et al. 1982; Tzanakakis and Koveos 1986). A sustained period of adult activity in June and July probably represents emergence of the second generation of adult OLF. From late July through early September, adult fly activity was very low in the San Joaquin Valley, a phenomenon considered a facultative or summer diapause and described by several European researchers (Fletcher et al. 1978; Kapatos and Fletcher 1984; Tzanakakis 1986; Tzanakakis and Koveos 1986). In September, a third emergence of flies was detected, followed in October through November by a sustained increase in adult flies, representing the fourth, and perhaps a fifth generation of OLF. Up to five generations of OLF have been reported in southern Europe (Tzanakakis 1986; Tzanakakis and Koveos 1986).

The much lower level of total fly collections in fall 2002 (fig. 1) was due primarily to the reduced numbers of flies found in the 15-trap Tulare County project, although the other two projects (PMA and Fresno County) also recorded fewer flies in fall 2002 compared with
2001. Comparisons of the three San Joaquin Valley trapping projects in 2002 (fig. 2) showed similar trends in fly collections through the year, but with some variations from week to week.

The PMA trapping data from commercial groves showed the most consistent pattern of OLF phenology over 2 years, and closely tracked the combined totals shown in figure 1 . This data also showed the relatively greater increase of flies collected in 2002 in the five northern locations (Madera to Exeter) compared with five southern groves (Lindsay to Bakersfield)(fig. 3). These collections demonstrate the continuing increase and expanding distribution of OLF populations from the southern San Joaquin Valley to the north, even in groves treated from mid-June to harvest with spinosad bait sprays. The bait applications, however, appeared to be effective in preventing economic damage to fruit, at least at the relatively low population levels experienced to date. No infestations were found in olives delivered to table olive canners in 2001 and 2002.

Trap data on the number of OLF generations per year in the San Joaquin Valley indicates that flies trapped from February to early March may represent adults overwintered from the previous fall. The increase in collections in late March and April could be new adults emerging from overwintered pupae. The short, sharp increase in May would then represent first-generation adults emerging from old crop olives infested by adults from February through April, and adult flights in June and July could be a second generation from eggs laid in 


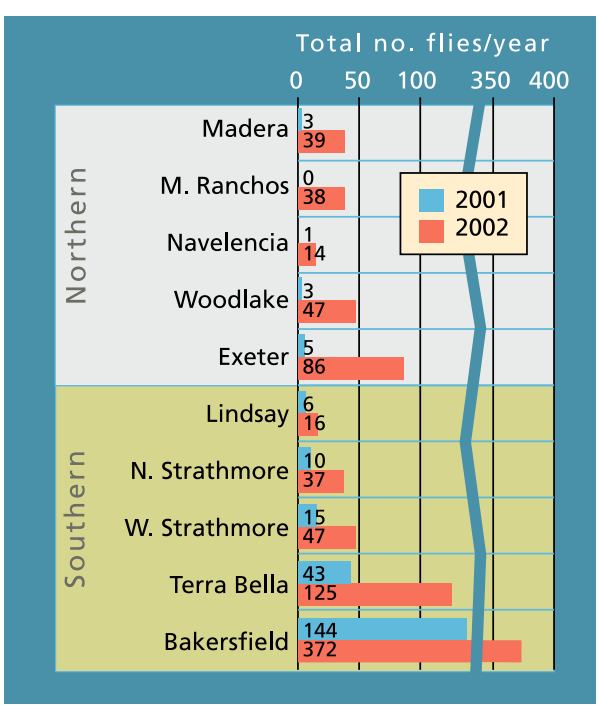

Fig. 3. Olive fly population distribution (numbers) and relative densities in San Joaquin Valley commercial olive groves, northern (Madera-Exeter) and southern (Lindsay-Bakersfield) trapping regions.

old crop fruit in April and May. These second-generation adults then lay eggs in new crop olives that become susceptible to oviposition beginning in mid- to late June; adults representing the third generation emerge in September. A fourth, and probably a fifth, generation then developed in October and November in the Central Valley. However, this hypothesis is speculative, and must be confirmed and validated by detailed studies on egg and larval development throughout the year in different climatic areas of interior California.

\section{Trap lure comparisons}

Equal numbers of traps with ammonium bicarbonate lures, and ammonia lures plus spiroketal pheromone lures, were placed in the 10 commercial San Joaquin Valley groves, allowing for comparisons of relative fly collections with the different lures. In traps baited only with ammonium bicarbonate lures, more male than female flies were col-

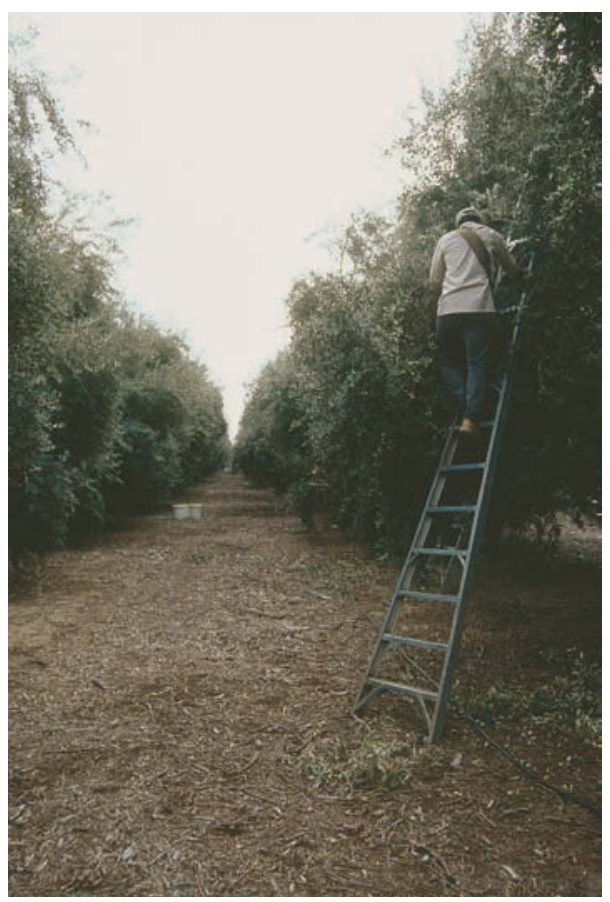

lected, at a ratio of almost 2:1 (table 1). Whether this represents the actual sex ratio in the OLF population could not be determined without rearing flies from pupae, but a 1:1 ratio would be normal (Moore 1962). However, Longo and Benfatto (1982) also noted more males than females in traps baited with ammonia attractants. As expected, the addition of spiroketal pheromone lures (a male sex attractant) to the ammonia lures increased collections of male flies approximately twofold, with little increase in female fly collections (table 1). Traps with only spiroketal pheromone lures were not included in this study, so comparisons of male response to the pheromone alone and to the other lures were not made.

\section{Southern California trapping}

In the coastal areas of Ventura and Santa Barbara counties, adult OLF collections were generally similar to patterns observed in the San Joaquin Valley
Olive flies were found year-round in southern and interior-central California, with varying levels of seasonal activity. So far, growers have been able to prevent economic damage to fruit by using spinosad bait sprays, integrated pest management and organic growing methods.

(fig. 4). However, individual sites, primarily in Ventura County, differed in numbers of flies collected between the cool, immediate coastal areas and warmer, drier areas only a few miles inland. These interior areas tended to have more flies than the coastal sites, perhaps due to temperatures warmer for optimum flight and fly activity during much of the day. Also, the midsummer (hot weather) depression of fly captures occurred earlier (May and June) and resumed earlier (August) in Ventura County than in the San Joaquin Valley; this event was not observed in Santa Barbara County in 2002. Adult flies were trapped in Ventura and Santa Barbara counties in all 12 months of the year, similar to adult OLF captures reported from northern Greece (McFadden et al. 1977). Coastal population fluctuations were also similar to northern Greece, with high populations in the spring from overwintered adults or immature stages, lower populations in midsummer and increasing populations from late July into the winter.

While OLF population trends on the coast generally were similar to the San Joaquin Valley, it was more difficult to distinguish discrete generations in the coastal climates. More flies were trapped in the winter on the coast than in the San Joaquin Valley, an expected result due to more moderate winter temperatures. It is also not unusual to find mature fruit from the previous year on trees along the coast until new crop fruit becomes susceptible to infestation in the late spring or early summer. The

TABLE 1. Number of male and female olive flies attracted to different lures in yellow-panel sticky traps

\begin{tabular}{llrrr}
\hline \hline Sex & \multicolumn{1}{c}{ Lure type } & 2001* & 2002† & Total \\
\hline Male & Ammonia & 54 & 199 & 253 \\
Female & Ammonia & 28 & 113 & 141 \\
Male & Ammonia plus pheromone & 118 & 384 & 502 \\
Female & Ammonia plus pheromone & 39 & 116 & 155 \\
\hline
\end{tabular}

* March 23-Dec. 31, 2001.

† Jan. 1-Dec. 27, 2002.

TABLE 2. Number of olive fly females with or without eggs, San Joaquin Valley, 2002

\begin{tabular}{lcc}
\hline \hline Month & With eggs (\%) & Without eggs \\
\hline February & $3(21.4 \%)$ & 11 \\
March & $27(35.5 \%)$ & 49 \\
April & $23(27.7 \%)$ & 60 \\
May & $15(15.6 \%)$ & 81 \\
June & $13(22.0 \%)$ & 46 \\
\hline
\end{tabular}


combination of available, susceptible fruit and moderate climate throughout the year could allow continuous reproduction of OLF on the Southern California coast, with six or perhaps even seven generations per year.

\section{Summer collections decline}

Reports from Europe suggest that a summer reproductive diapause in OLF is due to high temperatures, low humidity and absence of fruit (Fletcher et al. 1978), which may cause a decline in fly response to trap lures. A similar correlation of hot weather and fly response to the traps was seen in the three San Joaquin Valley projects in 2001 and 2002, with fly activity declining as maximum daily temperatures rose above $90^{\circ} \mathrm{F}$, but increasing whenever temperatures fell into the $70^{\circ} \mathrm{F}$ to $85^{\circ} \mathrm{F}$ range.

\section{Mating status of female flies}

The maturity and mating status of female flies was determined at various times during this study. The sexual maturity of collected flies, defined as females with eggs, was never high (table 2), but at least some of the trapped females were still immature. However, we expected many unmated females would eventually mate because of the number of male flies present. Females mated in the late winter to early spring infest old crop fruit to produce a new generation of flies in late spring and early summer.

Dissections and examination of female flies trapped in the San Joaquin Valley from June through September 2001 and the spring months of 2002 showed female flies with eggs present in every month from June through November 2001 and February through

TABLE 3. Number of mated and unmated OLF females in San Joaquin Valley, 2001-2002*

\begin{tabular}{lcc}
\hline \hline Date & Mated & Unmated \\
\hline June 2001 & 6 & 3 \\
July & 4 & 2 \\
August & 1 & 3 \\
September & 8 & 6 \\
October & 11 & 5 \\
November & 1 & 1 \\
June 2002 & 7 & 6 \\
\hline * Sexually mature, with eggs. & &
\end{tabular}
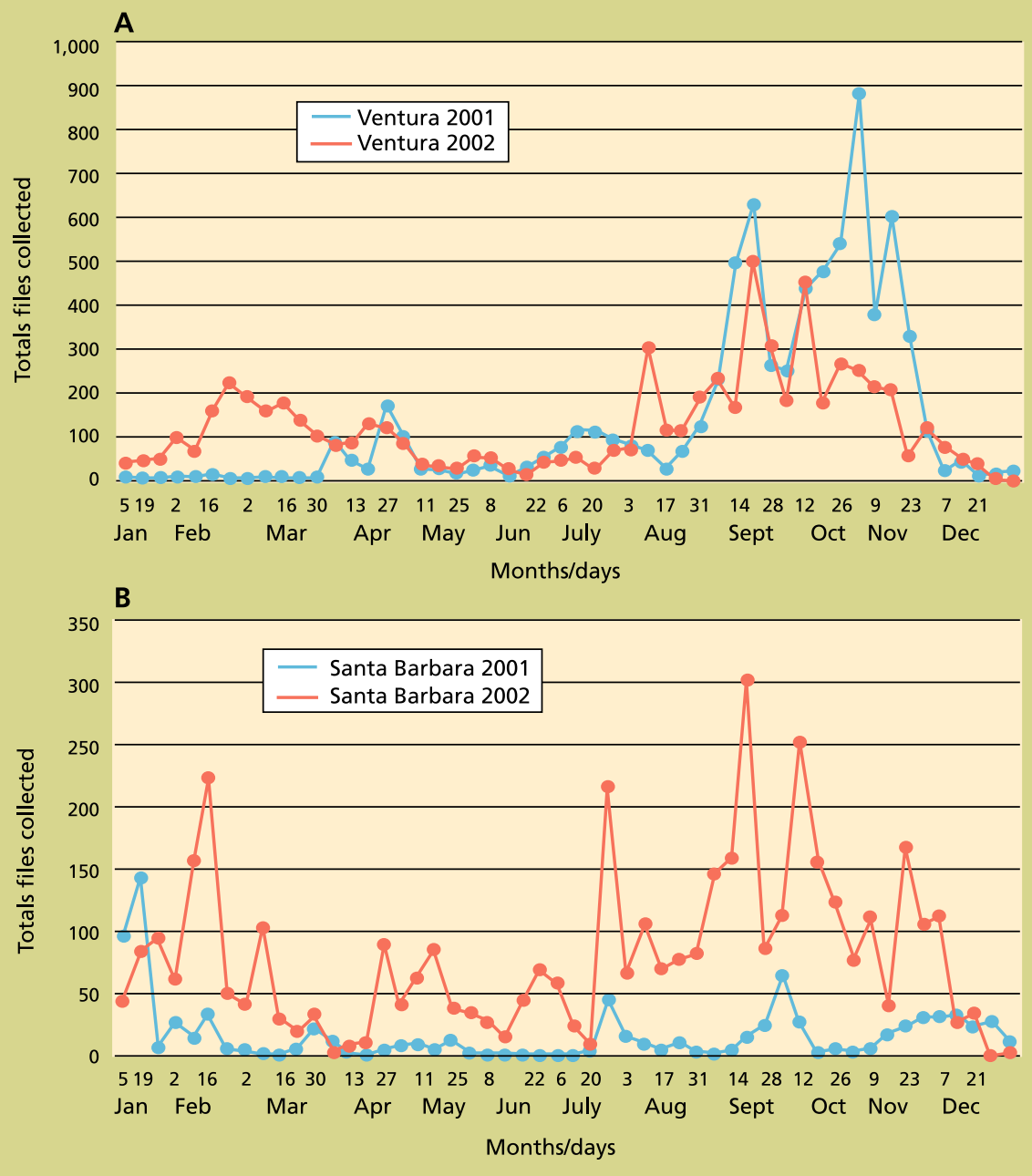

Fig. 4. Total olive flies trapped per week in (A) urban and rural Ventura County (16 traps) and (B) urban Santa Barbara County (14 traps), 2001-2002.

June 2002 (table 2). Michelakis (1986) reported a decline in mature female flies (with eggs) during hot weather, but noted that some portion of the female OLF population was always mature. Tzanakakis and Koveos (1986) observed a similar effect in conjunction with long day length. Observations from the San Joaquin Valley indicate that olives, even in hot weather, can become infested as soon as the fruit becomes susceptible to oviposition, usually in mid- to late June. In cooler coastal climates, OLF could infest either old or new crop fruit as soon as the females are mated, at any time of the year.

To determine the mating status of mature female flies, Eric Fisher of the California Department of Food and Agriculture dissected subsamples of female flies and examined them for sperm in their spermathecae. These examinations showed a relatively high percentage of mated females in June of both years and fall 2001, but a low mating percentage during hot weather in August (table 3). The presence of mature, mated females in June coincided in 2001 and 2002 with pit-hardening and initial susceptibility of new crop fruit to oviposition and larval development.

\section{Population dynamics of OLF}

The trapping data from coastal southern and interior central California showed that olive fly adults are present and active throughout the year, although populations were, as expected, low in the cold winter and hot summer months in the San Joaquin Valley. In the more moderate coastal climates, olive fly activity varied throughout the year, 
allowing for continuous breeding and reproduction in warmer, more protected areas, depending on the availability of host fruit on trees or the ground.

Reasons for the significant differences in fly collections between September and October in 2001 and 2002 in the San Joaquin Valley are not readily apparent. Even with low populations in late 2002 , continued spring trapping in the 10 commercial groves in 2003 showed, as in 2001, much higher fly collections than in early 2002 (PMA, unpublished data). Continued research should provide valid explanations for these yearto-year and seasonal fluctuations. There were distinct differences in fly densities and activity in the coastal areas (fig. 4) by year and area; monitoring of olive fly phenology and behavior is needed in microclimates as well as regions to select and optimize management strategies.

We still have much to learn about control and management of olive fly in California. While our data is to a certain degree preliminary, it provides the foundation for continued research on the relationships between macro- and microclimates, fly behavior and phenology, fruit development and susceptibility of table and oil cultivars to infestation, and a better understanding of when and how to apply various integrated pest management (IPM) strategies such as bait spray applications, trapping options, parasite releases and harvest timing. An olive fly phenology model based on trapping and temperature, for example, could be used to determine optimum harvest timing, or the release of parasites in urban trees or organic olive production; such studies are under way.

\section{R.E. Rice is Entomologist Emeritus, De-} partment of Entomology, UC Davis and Kearney Agricultural Center, Parlier; P.A. Phillips is Central Coast IPM Advisor, UC Cooperative Extension (UCCE), Ventura; J. Stewart-Leslie is Pest Control Advisor, Pest Management Associates, Exeter; and G.S. Sibbett is Farm Advisor Emeritus, UCCE
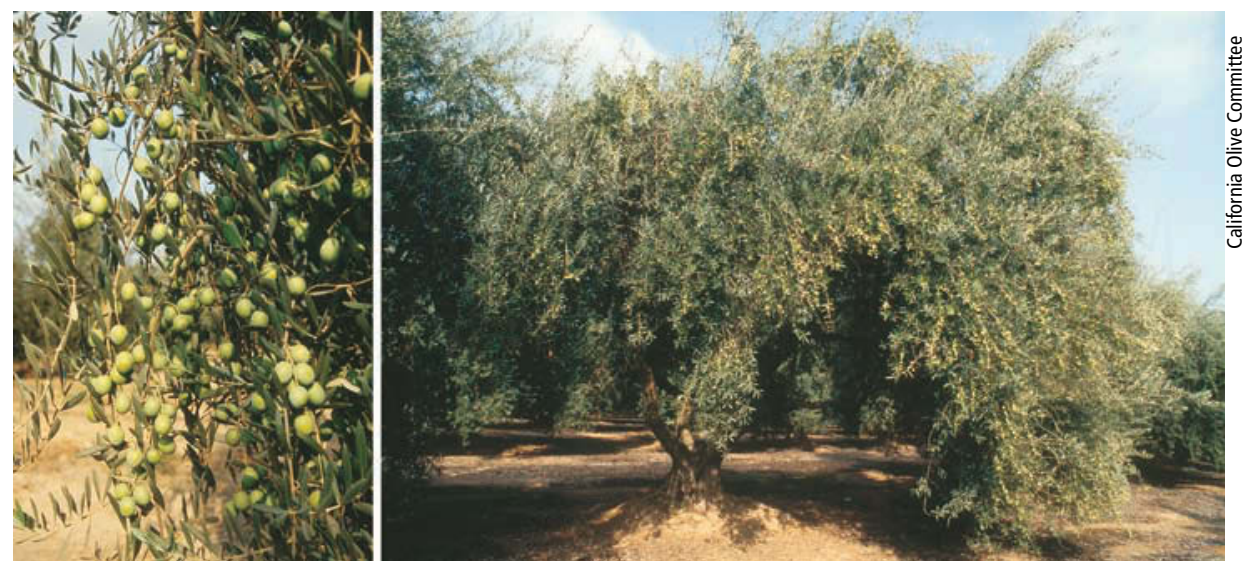

California supplies $99 \%$ of the commercial olives grown in the United States, with 134,000 tons harvested on about 36,000 acres in 2001. Trapping data will aid in the development of pest-control strategies to manage the olive fruit fly.

Tulare. The cooperation and free exchange of information from European colleagues and researchers has been invaluable to California olive growers in formulating a response to the olive fruit fly. In particular, we thank G.E. Haniotakis, O.T. Jones, A.P. Economopoulos and A. Montiel-Bueno.

We also thank E. Fisher, California Department of Food and Agriculture (CDFA), for determinations of the mating status of female flies; CDFA for financial support and trapping supplies; Janet Nelson and the California Olive Committee for encouragement and financial support; and the many growers who provided access to their groves for these studies.

\section{References}

[CDFA] California Department of Food and Agriculture. 2002. California Agricultural Resource Directory. Sacramento, CA. 176 p. Economopoulos AP. 2002. The olive fruit fly, Bactrocera (Dacus) oleae (Gmelin) (Diptera: Tephritidae): Its importance and control; previous SIT research and pilot testing. Report to International Atomic Energy Agency (IAEA), Vienna, Austria. 44 p.

Economopoulos AP, Haniotakis GE, Michelakis S, et al. 1982. Population studies on the olive fruit fly, Dacus oleae (Gmel.) (Dipt., Tephritidae) in Western Crete. Z Ang Ent 93:463-76.

Fletcher BS, Pappas S, Kapatos E. 1978. Changes in the ovaries of olive flies, Dacus oleae (Gmel.) during the summer, and their relationship to temperature, humidity and fruit availability. Ecol Entomol 3:99-107.

Haniotakis G. 1986. Effect of size, color and height of sticky traps on captures of $\mathrm{Da}$ cus oleae. Entomologia Hellenica 4:55-61.

Kapatos ET, Fletcher BS. 1984. The phenology of the olive fly, Dacus oleae (Gmel.) (Diptera, Tephritidae), in Corfu.

Z Ang Ent 98:360-70.

Longo S, Benfatto D. 1982. Observation on olive fly (Dacus oleae (Gmel.)) - Popula- tion dynamics in Sicily. Proc CEC/IOBC Int Symp, Fruit Flies of Econ Importance. Athens, Greece. Rotterdam: AA Balkema. p 612-5.

McFadden MW, Kapatos E, Pappas S, Carvounis G. 1977. Ecological studies on the olive fly Dacus oleae (Gmel.) in Corfu. I. The yearly life cycle. Estr dal Boll del Lab Entomol Agraria "Filippo Silvestri" di Portici 34:43-50.

Michelakis S. 1986. Bio-ecological data of the olive fly (Dacus oleae (Gmel.)) in CreteGreece. In: Proc Second Int Symp on Fruit Flies. Crete, Greece. Amsterdam: Elsevier Science. p 397-405.

Michelakis SE. 1990. The olive fly (Dacus oleae (Gmel.)) in Crete, Greece. Acta Horticulturae 286:371-4.

Montiel-Bueno A. 1986. The use of sex pheromone for monitoring and control of olive fruit fly. In: Proc Second Int Symp Fruit Flies. Crete, Greece. Amsterdam: Elsevier Science. $\mathrm{p}$ 483-95.

Moore I. 1962. Further investigations of the artificial breeding of the olive fly Dacus oleae (Gmel.) under aseptic conditions. Entomophaga VII:53-7.

Phillips PA, Rice RE. 2001. Olive fly trapping surveys in Southern California. UC Plant Prot Quar 11(1):1-3. www.uckac. edu/ppq.

Ramos P, Jones OT, Howse PE. 1982. The present status of the olive fruit fly (Dacus oleae (Gmel.)) in Granada, Spain, and techniques for monitoring its populations. In: Proc CEC/IOBC Int Symposium, Fruit Flies of Economic Importance. Athens, Greece. Rotterdam: AA Balkema. p 38-40.

Rice RE. 2000. Bionomics of the olive fruit fly, Bactrocera (Dacus) oleae. UC Plant Prot Quar 10(3):1-5. www.uckac.edu/ppq.

Todd FE. 1929. The olive fly (Dacus oleae Rossi). Mo Bull Calif Dept Agric 18(10):527-33.

Tzanakakis ME. 1986. Summer diapause in the olive fruit fly and its significance. In: Proc Second Int Symp Fruit Flies. Crete, Greece.

Amsterdam: Elsevier Science. p 383-6.

Tzanakakis ME, Koveos DS. 1986. Inhibition of ovarian maturation in the olive fruit fly, Dacus oleae (Diptera: Tephritidae) under long photophase and an increase of temperature. Ann Entomol Soc Amer 79:15-8. 